\section{A prática do Direito e o seu ensino nas Faculdades de Direito nos Estados Unidos e no Brasil}

(Extraído de um artigo de William F. Braith Waite - The Great Ideas Today, 1989). Citação apenas parcial.

Aula inaugural 1993

\section{Peter Walter Ashton}

Diretor da Faculdade de Direito UFRGS

Segundo dados estatísticos, até o ano 2000, provavelmente, os Estados Unidos terão um milhão de advogados. Um para cada 300 americanos. É muito advogado. Isto é bom ou não?

Nenhuma nação ocidental desde os tempos do tardio Império Romano contou com tantos profissionais do direito.

Os cidadãos americanos do século 20 acreditam que a lei e os advogados sempre andam juntos, mas tal combinação é em verdade meramente convencional. Embora circunstância do nosso tempo, a justaposição lei + advogado não é da natureza das coisas.

A primeira lei do homem branco, no continente norte-americano, foi o acordo "Mayflower" assinado em Cape Cod Bay em $11 / 11 / 1620$, por ocasião da chegada dos peregrinos puritanos na América do Norte.

Durante no mínimo 100 anos e após a assinatura deste pacto, os colonizadores imigrantes viveram e trabalharam sem a assistência e presença de advogados. O historiador Charles Warren em seu livro "A Históri da Ordem dos Advogados Norte-Americana - American BAR", em 1911, assinala esta peculiaridade. Em sua introdução, fala de um direito sem advogados.

No entanto, ao chegar o ano de 1776 , os advogados e a profissão do direito já estavam bem estabelecidos nas colônias americanas. Da convenção constitucional de 1787 em Filadélfia, participaram muitos advogados bem como pessoas versadas no direito.
Todavia, mais de um século teria de passar, somado à "marcha para o Oeste" e à implantação da "Revolução Industrial" nos EEUU, para finalmente surgir uma organização nacional de advogados, a American Bar Association, subdividida em sessões locais e estaduais. De fato, a ABA conta com pouco mais de um século de existência, pois foi fundada no ano de 1878

Constata-se pois que no passado existiram comunidades que tinham leis mas não advogados.

Nos tempos bíblicos israelitas, sob as leis de Moisés, derivadas dos Mandamentos, a vida nestas comunidades de antigos judeus era minuciosamente legislada, a tal ponto que, hoje em dia, consideraríamos tal regulamentação opressiva. No entanto, se o Vetho Testamento é aceito como informação fidedigna, advogados, no sentido próprio da palavra, eram raríssimos. A administração das leis estava nas mãos dos sacerdotes, juízes e reis. Não muito diferente do sistema adotado pelos egípcios.

Quem leu a biografia de Licurgo, escrita por Plutarco, constata que na antiga Esparta inexistia qualquer lugar ou oportunidade para advogados militantes exercerem sua profissão. Não obstante isso, Esparta tinha um amplo corpo de leis, e a vida dos espartanos, tal qual a dos israelitas, era regulada, pelas leis em vigor, mais como se fosse a vida num campo de prisioneiros do que a de cidadãos de uma sociedade civil.
Homens e mulheres comiam, dormiam e viviam separados, excetuadas as visitas conjugais. O serviço militar era obrigatório para todos os homens e propriedade privada não existia. Inexistindo entre os esparta nos a propriedade privada, inexistia o comércio e, não havendo comércio inexistiam as disputas comerciais, atividad predileta da prática quase diuturna dos advogados americanos de hoje em dia.

Atenas, a cidade vizinha ao norte de Esparta, rival e mais liberal, possuía o comér cio e colônias e, portanto, frotas navais mi litares e comerciais poderosas. Mas, afora isso, a situação era a mesma. Pois, embor o comércio florescente de Atenas causasse disputas comerciais e fizesse surgir um direito comercial/naval no século quinto an tes de Cristo, em Atenas, tal corpo de leis comerciais não produziu advogados. A litigação era pro se, quér dizer: cada pessoa era seu próprio advogado.

Havia, sim, redatores profissionais de discursos - os sofistas - e eram - lhes pagos honorários para que redigissem argumentos legais e jurídicos ou para que ensinassem ao cliente litigante como apresentar tais argumentos. Advogados, no entanto, como os conhecemos hoje em dia, isto é, um profissional do direito no emprego ou sob outorga de mandato de outrem, não existiam nem mesmo em Atenas. Havia leis, comér cio, litígios, retórica e professores de retórica. Não existiam, entretanto, advogados.

Conclui-se daí que, em tese, uma comunidade política precisa ter leis, indubitavelmente, mas também parece ser claro que um sistema legal, implantado e em funcionamento, não precisa ter, necessariamente, advogados.

Deste ponto de vista não parece haver uma resposta a priori, satisfatória, à questão se um país, os Estados Unidos, por exemplo, está em situação melhor ou pior com um grande número de advogados. A resposta depende daquilo que o advogado faz, do que deveria fazer e depende ainda da sociedade de cada país.
No Brasil, o exercício da profissão de advogado é assegurada constitucionalmente pelo artigo 133 da C. F. que diz:

"O advogado é indispensável à administração da justiça, sendo inviolável por seus atos e manifestações no exercício da profissão nos limites da lei".

Thomas Hobbes em seu livro $O$ Levia than, escrito em 1651, já disse que "os magistrados e outros oficiais da judicatura e da execução das leis são as juntas da sociedade; as leis e a equidade, uma vontade e uma razão artificiais". Esta metáfora parece correta já que as leis consertam e viabilizam o que a sociedade procura atingir e conseguir realizar. Modernizando a metáfora de Hobbes, teríamos que incluir nela os advogados que, como o diz nossa Constituição, são indispensáveis à administração da Justiça.

A Revista Jurídica americana National Law Journal, em 1985, assim definiu as funções do advogado moderno:

"As formas, segundo as quais os advogados exercitam o seu poder, são tão diversas e complexas como o é a própria sociedade".

"Advogados são conselheiros dos líderes empresariais nacionais e regionais. Como tais, auxiliam na formação da economia".

"Há advogados que são especialistas em política, atuam nos bastidores e influenciam os governos em grau surpreendente. Como profissionais militantes, atuam em causas judiciais que envolvem e afetam praticamente todo cidadão. Como pesquisadores e intelectuais passam adiante, de geração em geração, a tradição jurídica e ensinam novas gerações de advogados como adaptar e modificar o corpo de leis para atender as exigências de uma sociedade que muda".

"Inexiste tendência ou programa comercial e governamental ou grupos de interesses especiais que não tenham, como assessores, ou mesmo dirigentes, advogados".

Assim pois, tanto nos Estados Unidos, como no Brasil, ou em qualquer outra nação ocidental, a presença do advogado na vida nacional é marcante e constante.

O meio político é sem dúvida o Milieu dos advogados. Os assuntos jurídicos e os negócios práticos/legais, a sua atividade 
principal. A prudência, a sua virtude preeminente. Nos EEUU e nas demais democracias ocidentais, o direito e a lei são tão abrangentes quanto a política, e o direito toca em quase todos os aspectos da vida política, e assim, sem dúvida alguma, os advogados, cujo instrumento de trabalho é o direito e a lei, tratam de tudo quanto é tocado pelo direito. Embora a política (no sentido do estrito) não seja o que a maioria dos advogados pratique a maior parte do tempo, diretamente ou indiretamente muito do que fazem os advogados influencia a vida política.

A grosso modo, 3/4, ou seja, $75 \%$ de todos os advogados americanos militam total ou parcialmente na advocacia autôno$\mathrm{ma}$, representando clientes privados.

Eis o que fazem, por exemplo, alguns advogados de defesa criminal norte-americanos:

a) - Na cidade de Nova York, F. Lee Bailey, um dos mais famosos advogados criminalistas de defesa americanos, escuta o depoimento da testemunha Roger Wilson Jr.

David W.C. Clark, cliente de Bailey, um advogado de Manhattan, é acusado de fraude nos Correios e Telégrafos, perjúrio e declarações falsas, afim de obter empréstimos bancários, bem como da prática de sonegacão do imposto de renda. Crimes de colarinho branco. Condenado pelos crimes imputados, Clark perderá o registro na ABA, irá para a prisão e pagará as multas e impostos atrasados. O depoimento judicial de Wilson, que acusa Clark de apropriação indébita de US\$ 3 milhões, é crucial para a defesa de Clark, e o exame deste depoimento, feito em detalhe por Bailey, pode decidir o futuro de seu cliente.

b) Bailey já defendeu clientes mais famosos. Por exemplo, o famoso estrangulador de Boston, o médico Sam Sheppard, o rumoroso caso de seqüestro, pelos Panteras Negras, de Patrícia Hearst, filha do famosíssimo superempresário de redes de jornais e TVs, Hearst.

O capitão do Exército dos USA acusado de liderar, em 1968, a matança indiscriminada de vietnamitas no vilarejo de My Lai, no Vietname do Sul.

50 c) - Bailey também foi um dos três principais advogados de acusação das vítimas hindus do acidente de Bhopal contra a poderosa Union Carbide.

\section{Os defensores públicos}

Já outra advogada, Stephanie Page, defensora pública, atuando em uma das varas criminais da cidade de Boston, prepara-se para conduzir outro depoimento crucial, o de seu cliente Lawyer Johnson, acusado de crimes urbanos de rua, assalto, tentativa de estupro, assalto a mão armada. Enquanto Clark, cliente de Bailey, era um advogado branco e super bem alimentado, para não dizer gordo, o cliente de Page é preto, pobre, com pouca educação e apresenta antecedentes criminais com pena de prisão. É típico para o tipo de cliente que Page defende.

A testemunha contra Johnson é um of cial policial cujo depoimento a respeito da identificação do assaltante, dada pela vítima, é inconsistente e contraditório. $\mathrm{O}$ argumento da defesa: identificação errônea. Page tentará ressaltar e pinçar as contradições do depoimento do oficial quanto à descrição física do assaltante. Se o júri não aceitar a teoria da defesa de Page, Johnson irá para a prisão, possivelmente por um longo período de tempo.

Os melhores escritórios de advocacia de Boston pagam a um advogado, sem prática, que inicia sua profissão, 70.000 dólares por ano, ou seja, quase 6.000 dólares por mês. Page, em 10 anos de prática de defensoria pública, ganha menos do que duas terças partes disto. Por que então persiste ela Page, em defender os pobres e prestar serviço público?

Eis o que ela diz a respeito: "Há muitas vítimas no nosso (americano) sistema de justiça. As vítimas de crimes são apenas algumas das vítimas. Nós permitimos que jovens terminem o "colégio", sem na verdade saberem ler e sem ter por isso qualquer expectativa de futuro".

O sistema americano de justiça criminal revela apenas a ponta do iceberg das vidas que os nosso pobres vivem. Estas pessoas vêm a mim sem esperanças. Eu não tere nenhuma dificuldade em praticar esta defensoria pública até que a sociedade resolva tratar todos, com certeza, de forma igual. Digo-lhes mais alguma coisa. Eu tiro proveito e satisfação do que faço".

"Quando evito que os policiais achaquem um vagabundo da rua, tenho certeza que evito que este vagabundo ao menos não entrará no seu dormitório. Realmente acre dito nisso. Acho que estou literalmente vi vendo a Constituição".

\section{Os advogados dos ricos}

Enquanto que a advogada e defensor pública Page extrai vitalidade e esperança para a sua missão pública, da Constituição, o seu trabalho deve parecer irrelevante para o que fazem os outros advogados.

Vejam, por exemplo, o caso Hunt. Estes irmãos riquíssimos do Texas: Lamar, Herbert e Bunker, em 1988, passaram a ser defendidos por um exército de advogados. Em agosto de 1988, uma companhia de mineração peruana, a Minpeco S.A., obteve um sentença condenatória (de júri), 'nos Estado Unidos, contra os três irmãos e outros no valor de 132 milhões de dólares.

A Minpeco alegou e provou que os réu manipularam fraudulentamente o mercado mundial de futuros em prata. $O$ teor $d a$ sentença e a certeza de terem que pagar alto honorários advocatícios de defesa levaram os irmãos Herbert e Bunker Hunt a confessar a sua autofalência. Eles também apelaram da decisão. O irmão Lamar Hunt pre feriu fazer um acordo separado e pagou idenizações no valor de 17 milhões de dólares. O subseqüente julgamento de júri e o processo de autofalência movimentaram ocuparam muitos advogados.

Para complicar as coisas ainda mais, Receita Federal americana entrou em juízo e passou a pedir o pagamento de mais 900 milhões de dólares em impostos sonegados dos Hunt e das suas esposas, mobilizando assim, dos dois lados, mais batalhões de advogados com forte poder de fogo profissional-legal. Segundo um relatório do jornal financeiro Wall Street Journal, baseado em documentos apresentados na Vara de Falências da Comarca de Dallas, os irmãos Herbert e Bunker pagaram honorários a nada menos do que 65 escritórios de advocacia estabelecidos desde as cidades de Anchorage no Alaska até Lima, capital do Peru. Quinze milhões de dólares de honorários em apenas um ano. Um dos advogados de defesa, cobrou 600 dólares por hora de consultoria e serviço legal.

\section{Os advogados dos pobres}

Tomemos como exemplo o trabalho do advogado Henry Rose, de Chicago. E o diretor e idealizador do "Centro Comunitário de Direito" da Universidade de Loyola. Toda a organização do Centro leva as suas marcas e são prova da sua determinação de atender as necessidades de assistência jurídica dos pobres, combinando tais necessidades com o laboratório jurídico que o centro comunitário oferece aos estudantes de direito.

Assim como no caso da advogada Page, o trabalho e a carreira de Henry Rose não são nem glorificados, nem muito conhecidos. Ambos são advogados que se propuseram uma missão. Ambos, acreditando de corpo e alma em seu trabalho, deliberada mente abandonaram as recompensas materiais da advocacia que seus ex-colegas de Faculdade obtém na advocacia particular. Existem centenas de advogados deste tipo nos EEUU. Muitos mais são necessários.

Henry Rose e seus 30 estagiários, treinados a cada semestre, advogam causas bem diferentes que as dos irmãos Hunt. Eis alguns dos casos advogados:

Dois ex-inquilinos são acionados em juízo pelo seu anterior locador por prejuízos de 900 dólares causados ao apartamento que antes ocupavam. O caso é acordado por 160 dólares:

- Um homem assaltado sofre lesões corporais graves e busca indenização do INSS do Governo Federal

Uma mulher é ré numa ação proposta por uma companhia de cartões de crédito por 300 dólares gastos pelo seu ex-marido 
depois do divórcio. Rose acorda o caso por 180 dólares;

- e tantos outros casos mais

A nova especialização do Direito

Ambiental.

A 15 minutos da advocacia de feijão com arroz do advogado Henry Rose, situa-se a famosa Rua La Salle, o centro de atividade política, comercial e jurídica de Chicago. Lá, alguns advogados trabalham num ramo do direito que há 20 anos era totalmente desconhecido. São advogados especializados em problemas jurídicos que surgem da poluição ambiental.

O escritório de advocacia Jones Day, Reavis e Pogue, de Cleveland, tem 18 advogados especializados em direito ambiental.

Um outro escritório de São Francisco tem 33.

Os problemas são os mais variados.

A EPA federal americana: Enviromental Protection Agency tem o poder de localizar e mandar limpar locais com lixo tóxico. Os proprietários passados e presentes de tais áreas de terras e todos quantos geraram o lixão podem ser e são responsabilizados pelas despesas geradas pela limpeza.

A empresa Outboard Marine Corporation, acusada de poluir a baia de Waukegan, Illinois, com lixo tóxico com PCB, acordou a demanda, pagando 29 milhões de dólares, numa ação judicial federal que tramitou 10 anos.

Fusões, incorporações e cisões de companhias sempre trazem embutidas em si o risco incalculável de responsabilidade por poluição ambiental. Às vezes tais transações são abandonadas ou modificadas, por esse risco. Um desses exemplos foi o malogro da compra da Indústria Química Koppers, pois os compradores em potencial assustaram-se com a potencial herança de responsabilidades por depósitos químicos de lixo tóxico.

Já existem tribunais estaduais america nos que responsabilizam por lixo tóxico ou outros fatores de poluição ambiental instituições financeiras que executam hipotecas e outras garantias contra companhias devedoras poluidoras.
Tais decisões fizeram com que mutuantes se tornassem relutantes em financia operações imobiliárias comerciais e industriais sem o prévio "bene placet" dado por especialistas em direito ambiental.

Em Nova Jersey, que tem a legislação ambiental mais exigente dos EEUU, quase todos os empréstimos financeiros com garantia real envolvem uma prévia investigação de responsabilídade ambiental.

\section{A promulgação de novas leis. As leis fiscais}

O direito positivo novo pode criar e cria novas especialidades para os advogados. As leis de proteção ambiental, como visto, são um exemplo. A nova legislação de proteção ao consumidor, a legislação societária, particularmente das sociedades por ações e obviamente o direito fiscal. A explosão populacional incontida, a ganância, a falta de educação, a migração interna, o inchaço das cidades, crescimento da miséria, a favelização, a falt de um planejamento e aconselhamento familiar humano, moderno e esclarecido, compelem, cada vez mais, os estados subdesenvolvidos, asiáticos, latino-americanos especialmente africanos a lançar mão do expediente mais simples ( $\mathrm{e}$ às vezes inconstitucional) direto para obter recursos. Usam e abusam da tributação da classe média, alta, dos assalariados mais abonados e dos proprietários de bens móveis e imóveis. As siglas do tributos são as mais diversas: ISSQN, IPTU, ICMS, IPI, IR, IPVA, para citar apenas alguns impostos dos mais corriqueiros.

Toda esta gama de tributos, mais de 50 no Brasil, supostamente destina-se exclusivamente a manter a máquina do Estado (Municípios, Estados e União) e implementar o bem comum, aqui também inseridos os menos afortunados. No entanto, como todos nós sabemos, o desperdício, certamente $20 \%$ do total, se não mais, a garantia de ganhos de grandes grupos corporativistas geralmente comprometem até $80 \%$ da arrecadação de tributos do Estado, pouco sobrando para investimentos no bem comum.

Dai então a importante missão do advogado de conhecer e estudar as leis fiscais, municipais, estaduais e federais para prote- ger os contribuintes de ilegalidade, inconstitucionalidades, etc, com a impetração de mandados de segurança, por exemplo. A área fiscal é repleta de leis que necessitam ser estudadas e testadas quanto à sua validade e legalidade.

\section{Missão dos advogados}

Também a legislação anti-trust, que nos Estados Unidos iniciou com o Sherman Act em 1890 e o Clayton Act de 1914, é um campo relativamente novo no Brasil. Há que advogar a causa do governo ou a defesa das empresas acusadas. Com a criação e reorganização do $\mathrm{CADE}$, subordinado ao Ministério da Justiça, um significativo elenco de leis anticartéis e anti-trust foi promulgado de 1986 até a presente data. Há aí trabalho para todos os advogados capazes.

\section{A influência da jurisprudência e tecnologia}

Novas especializações em direito, podem também surgir de decisões jurisprudenciais Nos Estados Unidos a responsabilidade decorrente da produção de produtos defeituosos origina-se quase que exclusivamente de decisões judiciais. Já no Brasil a Lei № 8078 , de 11/09/1990, que dispõe sobre a proteção do consumidor, assumiu integralmente este papel.

Avanços na tecnologia e nas ciências po dem gerar novas especialidades para o advogado. Por exemplo, o direito aeronáutico e espacial. Ou ainda, problemas jurídicos que surgem de avanços na pesquisa médico-farmaco-genética. Fertilização in vitro, artificial, contratos com mães de aluguel, prolongamento artificial da vida dos acidentados e idosos, tratamentos de geriatria, a adoção de características especiais e problemas vinculados com a AIDS, a síndrome da deficiência imunológica adquirida, para citar apenas algumas das novas áreas capazes de criar litígios. Destarte, a área da prática da advocacia pode ser definida pelo tipo de pessoas atendidas, por exemplo: "imigrantes", estrangeiros, idosos, infectados, inférteis, médicos, etc. Pode ainda ser definida pelo setor econômico: direito securitário, bancário, financeiro, concessionárias públicas ou pelo objeto de que trata: direito criminal, direito de família, direito imobiliário, locatício, propriedade intelectual (marcas e patentes, sinais de propaganda, etc.).

Um dos ramos do direito mais especializados nos EEUU é o dos acidentes pessoais (personal injury law).

Nesta área advogam milhares de advogados. As especializações são muitas. Aci žentes na construção civil, na viação aérea, rodoviária, trânsito, ferroviária, medicina, etc.

No Estado de Illinois, por exemplo, o Dram Shop $A c T$ pode viabilizar a responsabilização do vendedor de bebidas alcoólicas pelos acidentes causados pelo freguês alcoolizado.

Este resumo dos ramos do direito nos quais atuam os advogados, embora lacunoso e incompleto, bem mostra a crescente legalização da sociedade, e a complexidade e diversidade das tarefas do advogado.

$\mathrm{A}$ isto, acresce a tendência dos americanos, já observada há mais de 100 anos por De Tocqueville, de converter problemas políticos, econômicos e sociais em processos judiciais, tendência esta que agora já é também manifestada no Brasil e na Constituição, dita "cidadã", de 1988. A diversidade e a complexidade da tarefa do advogado na sociedade moderna reflete a característica do direito como uma instituição políticosocietária. O direito é onipresente na nossa Polis e por conseguinte, as tarefas do advogado são, comensuradamente diversas, complexas e onipresentes, reflexo do tipo de sociedade do século vinte, construida pelos americanos e demais democracias ocidentais.

\section{O trabalho do advogado e a ética}

Qual o verdadeiro cerne, o núcleo do trabalho, da profissão do advogado?

Será possivel obter uma resposta satisfatória elencando todas as especializações do direito praticadas pelos advogados? 
Ou será, pelo contrário, a resposta dada pela própria lei ao definir e estabelecer o que o advogado deveria fazer?

$\mathrm{Na}$ primeira hipótese, o método a ser utilizado será o indutivo, isto é, a coleta de detalhes para chegar à formulação de uma generalização. E o método do historiador e do cientista social.

De acordo com a segunda hipótese, usase o método dedutivo. Inicia-se com definições e axiomas e segue-se uma seqüência de inferências lógicas. É o método utilizado pelo filósofo do direito natural que utiliza como instrumentos de indagação obras tais como a Bíblia; as Leis de Platão; A política de Aristóteles:; o Tratado sobre o Direito de Santo Tomás de Aquino; Os Dois Tratados Sobre o Governo (o segundo volume apenas) de Locke: o Leviathan de Hobbes e outras obras que analisam a evolução das leis e do direito de cada país.

\section{O direito como profissão pública}

Fundamentalmente é obrigação do advogado servir ao cliente e ao bem comum ao mesmo tempo. Nem sempre o cliente busca obter o que é bom para ele e para a comunidade em que vive. É então obrigação do advogado aconselhar o seu cliente no sentido de não prejudicar-se a si mesmo e tampouco à comunidade em que vive. $\mathrm{O}$ advogado que não cumpre com este dever infringe o Código de Ética Profissional e não atende aos melhores interesses do seu cliente. Deve, pois, o advogado julgar quais são os melhores interesses do seu cliente, já que este, muitas vezes, não tem a capacidade de fazê-lo. A maioria dos clientes sabe disto Eles procuram obter, esperam obter, estão dispostos a pagar pela formulação de um julgamento ou conselho imparcial. O advo gado que frustra esta expectativa do seu cliente engana o mesmo, quebra o princípio de confiança e ainda por cima comete o estelionato. Advogados experimentado aprenderam a ouvir com interesse, mas RESERVA, as "histórias" dos seus clientes. O clientes sempre acreditam que sabem o que querem, nem sempre o que deveriam saber.
Mais raramente ainda, sabem o que a lei hes pode conceder e quase nunca sabem que realmente merecem.

A lei reconhece e sabe que os homens podem ser e são egoístas e que o egoísmo não contido e controlado pode destruir uma comunidade.

Os fundadores da democracia norte-americana já tinham constatado isto. Nos "Papéis Federalistas", encontra-se esta frase: "Se os homens fossem anjos, não haveria necessidade de governo". Todavia o individuo e a comunidade são inseparáveis, tanto teór ca quanto praticamente.

Já escreveu Aristóteles em sua Política:

"O homem isolado - incapaz de participar dos benefícios da associação política, ou que não necessita participar por já ser autosuficiente - não faz parte da Polis e portanto é ou uma besta ou um deus".

Por tudo isto, a prática do advogado precisa ter uma fundamentação ética. Se possuir tal fundamentação, o advogado pode considerar-se também um arquiteto, arquiteto da construção da sua honorabilidade e reputação de decência bem como arquiteto da construção de uma comunidade decente para os seus filhos e seus vizinhos.

Doutra forma, apenas será um mero intermediário, ou, algo pior, se vende a sua competência técnica aos desígnios egoístas de homens ambiciosos e ávidos de poder e pecúnia.

Os advogados nas democracias ocidentais têm portanto um duplo dever. Têm deveres para com o cliente e também para com a lei. Para com o indivíduo, mas também para com a comunidade em que militam e que é mantida pela lei.

Assim, tanto nos Estados Unidos, como no Brasil, as características do advogado são ultima Ratio determinadas pelo direito e pela legislação em vigor no país, conjunto de normas que se constituem em uma verdadeira constituição política nacional.

É preciso perguntar-se: qual a relação entre a lei e o advogado. Será que a lei faz o advogado ou o advogado faz a lei?

Será o advogado o mestre do direito e da

lei ou será ele o seu servo?

Qual será a visão correta?
O direito e a filosofia do direito

A política, em toda a sua amplitude, compreende todas as ações e atividades de convivência da comunidade.

Nas comunidades políticas norte-americanas e brasileira, o direito compreende-se como co-extensivo com a política. O direito toca todos os assuntos políticos e tudo o que o direito toca atrai advogados. Portanto a questão da indagação a respeito do caráter do advogado é uma espécie de quaestio política.

O esforço de chegar-se ao âmago verdadeiro das questões políticas é assunto da filosofia política, e no ocidente é tido como óbvio que a filosofia política deve-se aos grandes pensadores gregos, principalmente Sócrates, Platão e Aristóteles. Contudo desde o século XVI, a filosofia política e sua filha, a filosofia do direito, passaram a sofrer fortes e novas influências. Assim a posição moderna a respeito do emprego do método próprio à investigação da verdade última das questões políticas, e por consequência das questões do direito, foi enunciada com absoluta nitidez numa passagem famosa de um livro infame: $O$ Príncipe de Machiavelli.

Diz a passagem do livro:

"... já que é minha intenção escrever algo de útil para o leitor que compreende, parece-me mais indicado buscar descobrir a verdade verdadeira das coisas, do que apenas a sua imaginação".

"Muitos imaginaram repúblicas e principados que nunca de fato existiram ou foram vistos. Isto ocorre, pois existe uma enorme distância entre o "como se vive" e o "como se deveria viver". Aquele que abandona "aquilo que é efetivamente feito" por "aquilo que deveria ser feito", vai à ruina e não se preserva. Pois o homem que deseja professar o bem em tudo, cairá entre os muitos que são maus".

Repetindo pois a indagação: Qual a verdade verdadeira em ser um advogado? constata-se: Aqueles que afirmam que esta verdade se encontra na prática, na militância do advogado, primeiro devem e precisam resolver a séria dificuldade que surge da "enorme distância" entre o "como se vive" e o "como se deveria viver".

As questões éticas e morais que se apresentam sempre e continuadamente na militância da advocacia precisam ser encaradas e resolvidas por todos os advogados. Neste mister é útil e importante lembrar-se do que estatui o item XIII do art. 87, da Lei 4215 de 27.04.63: "é dever do advogado: recusar patrocínio de causa que considere imoral ou ilícita, salvo a defesa em processo criminal."

Também o art. 103 da mesma lei, que trata das infrações disciplinares, vale aqui lembrar:

"Constitui infração disciplinar: advogar contra literal disposição da lei, presumida a boa fé e o direito de fazê-lo com fundamen to na inconstitucionalidade, na injustiça da lei ou em pronunciamento judicial ante-

E ainda no inciso XXV "praticar, no exercício profissional, ato que a lei define como crime ou contravenção".

Vale a pena, a respeito do tema da "Causa Justa", ler Ruy de Azevedo Sodre: A Etica Profissional e o Estatuto do Advogado. LTR 1975, p. 95.

A problemática da ética na profissão do advogado é pois de suma importância.

Não deve o advogado aspirar somente ao lucrum, isto é, à riqueza, também não somente ao poder.

Quando advoga, lhe seria útil lembrar-se do que escreveu Santo Tomás de Aquino na Summa Theologica:

"A lei é uma ordenança da razão, elaborada e promulgada para o bem comum, por aquele que tem a responsabilidade pela $\mathrm{co}^{-}$ munidade".

Ora, o bem comum nada mais é do que num sentido geral, a obtenção e aplicação da justiça. De acordo com este enfoque, o advogado passa a ser um ministrador da lei que se preocupa com o bem comum.

É portanto neste sentido que se entende o advogado como "um oficial do sistema legal", comovestabelecem as regras padrões da American Bar Association.

$\mathrm{O}$ advogado militante, na sua prática advocatícia quando representa interesses pú- 
blicos ou privados, deve, acima de tudo, prática advocatícia daqui a 100 anos? Estaargumentar com a jurisprudência, a doutri- mos ou não em decadência?

na e com a lei. A argumentação jurídica, verbal e escrita, deve ser e é um hábito característico do advogado. $\mathrm{O}$ advogado ar gumenta para detectar a verdade nas alegações do seu cliente, para analisar citações doutrinárias e jurisprudenciais aparentemente contrárias à posição tomada pelo seu cliente e para sopesar a importância da autoridade judiciária, legal ou política institucional que cita.

É esta também a razão porque os estudantes de direito devem estudar com afinco as leis e a jurisprudência dos tribunais su periores.

O verdadeiro advogado é pois aquele que aprendeu a discernir, deliberar e argumen tar a respeito daquilo que é legal e ilegal, daquilo que é justo e injusto. Enquanto estadistas, políticos, legisladores e executivos também deliberam, argumentam, o ce ne do seu discurso é diferente daquele do advogado. Eles argumentam e discutem respeito do que existe, é conveniente ou vantajoso. Apenas o advogado tem o dever profissional de argumentar a respeito do que é lícito à luz do que é justo.

O profissional do direito como advogado em um estado técnico-comercial

Já Cícero afirmava que o essencial no preparo de um argumento é a procura das razões e motivos para sustentar o raciocínio. Esta tarefa era a inventio dos retórico latinos que era acoplada à dispositio, ou seja, à montagem e arrumação destes argumentos. A deliberatio, palavra que vem de libra (balança), é a escolha, a sopesagem de alter nativas e possíveis formas de agir e apresentação dos argumentos.

Indaga-se se a retórica forense e o discurso jurídico legal escrito, de hoje em dia, é satisfatório.

Será que os advogados de hoje em dia servirão de exemplo aos advogados do futuro? Será que seus argumentos escritos, de hoje, serão consultados como exemplos de 56 tanto da moral, do caráter, quanto do atuam nessas áreas.

\section{A retórica e a linguagem}

Dada a tremenda importância da linguagem para a advocacia - petições, recursos, contra-razões, memoriais, todas as peça processuais básicas, não há dúvida que domínio da língua, do vernáculo, é condição sine qua non para ser um bom advogado.

A televisão e a mídia propagandistica sem dúvida tiveram um impacto direto sobre o nível de capacitação linguística e argumentativa dos jovens nos últimos anos.

A televisão simplifica tudo ao extremo.

As mensagens sempre são de impacto, tudo é encenado de maneira tal a viabilizar imagem impacto. O comentário, a comunicação, extremamente simplificados, passam a segundo plano.

Resulta que há quarenta anos, desde o início dos anos cinqüenta, a fórmula $\mathrm{d}$ linguagem simplificada e até mesmo tosca da mídia televisionada afeta negativamente a qualidade da linguagem usada na política nas campanhas políticas, no discurso público e nas lides forenses. Embora a televisão não esteja presente ainda, usualmente, na sala de audiências, os seus efeitos são sentidos fortemente, já que a memória das pessoas que militam na justiça faz parte dos que assistem televisão. Embora o rádio e o jornais continuem conosco, a fonte primeira e primária da informação de que dispomos é a televisão. $O$ resultado direto deste fato incontestável é uma sensível diminuição, entre os mais jovens, da "capacidade de leitura, o que se reflete, catastroficamente, nos acadêmicos das faculdades de direito que, quando lêem, lêem mal e, portanto, escrevem ainda pior".

Ler bem é uma tarefa mental que exige treino, prática e esforço.

Assistir a programas de televisão não ajuda em nada a desvendar esta prática de leitura tão essencial à advocacia.

$O$ advogado precisa saber escrever, fala e ler bem, utilizar precisa e corretamente o vernáculo. A mídia televisiva, neste particular, em nada ajuda. E os resultados estão aí. Já não mais se escreve, peticiona, recorre, sustenta, argumenta como antigamente.
Tudo é quase sempre artificial, simplificado, rapidinho, tosco e insípido. As provas dos acadêmicos de direito, então, são, via de regra, em estilo telegráfico troglodita.

Isto precisa mudar. Deve haver um esfor-

co consciente e concentrado, de parte do corpos docentes das faculdades de direito, no sentido de exigir mais leitura e pesquisa dos estudantes de direito.

Outro aspecto negativo na prática atual da advocacia é a ênfase que é dada às aparências, ao Show. O visual, a teatralidade, o causar "boa impressão", passa a ser mais importante que a substância dos argumentos jurídicos.

Pode ser coincidência, mas o atual estado das coisas, a nosso ver, tem muita vinculação com o advento da televisão.

\section{O computador e a prática do direito}

Os escritórios de advocacia, em geral, converteram-se em locais onde está presente a alta tecnologia. Sistemas telefônicos complexos e completos, máquinas de datilografia eletrônicas com memória e impressoras, fax, telex, fotocopiadoras, etc. Mas principalmente a presença do "PC", Personal Com puter tem revolucionado a tarefa dos advogados de redigir petições e recursos, bem como pesquisar acórdãos e leis. $O$ que deve ser criticamente indagado é se a utilização do computador melhorou o desempenho dos que trabalham com e na justiça. A resposta, ainda parcial e incompleta, até agora colhida, é tanto sim quanto não.

Sim, se for considerado o mero trabalho cartorário e a ordenação dos processos. Não, se for considerada a qualidade do trabalho de redação forense dos advogados.

Todos os textos computadorizados são geralmente de uma simplicidade e banalidade constrangedoras. A fabricação em série de petições e recursos está se instalando cada vez mais, com textos e redações extremamente toscas.

É preciso que se diga e registre que embora importante encontrar um acórdão afeiçoado ao caso, ou o texto legal que resolva o problema, o verdadeiro caminho para en 
contrar a resposta certa para qualquer problema jurídico é aplicar os princípios básicos do direito, e provar que o cliente tem razão.

Para conseguir isto, nenhum computador será de utilidade ou ajuda.

Para o computador todos os acórdãos juízes, textos legais e de doutrina são iguais. Ele não discrimina entre argumentos superficiais e argumentos de peso. $\mathrm{O}$ advogado que necessita ler o material pesquisado sopesar a validade dos argumentos bons convincentes, vitais e talvez até cruciais para o seu caso. Portanto, de nada adiantara apresentar em juízo um grande número de acórdãos com artigos de doutrina pesquisados com o auxílio do computador, pois uma boa argumentação legal, baseada em princípios fundamentais do direito, poder derrubar os argumentos pesquisados ciberneticamente.

"Para saber e conhecer o direito como ciência, é preciso dominar suas doutrinas princípios básicos".

"O advogado dotado destes conhecimentos intrínsecos e capaz de aplicar e usá-los adequadamente com facilidade para resol ver os rolos entrelaçados das relações interpessoais, será o verdadeiro advogado e portanto a aquisição desta maestria do direito deveria ser constante preocupação de qua quer estudioso do direito. Todas estas doutrinas jurídicas fundamentais alcançaram seu estágio atual no mundo do direito através de lentas progressões. Representam estas doutrinas algo como um crescimento vivo em constante expansão e atualização, muitas vezes através dos séculos. Desta evolução podem ser traçada as suas origens, que devem ser pesquisadas e conhecidas.

número de doutrinas legais fundamentais é bem menor do que se supõe normalmente e de nada adianta citar inúmero acórdãos como precedentes, já que a maioria deles são de pouca utilidade e não servem para a realização de qualquer estudo jurídico sistemático."

Christopher Columbus Langdell "Contracts", 1871

Diretor da Faculdade de Direito de Harvard, 1870-1895.
É preciso deixar bem claro também que a velocidade do computador nem sempre convém ao direito.

O direito precisa de pressa deliberada e sedimentação. E qualquer deliberação toma tempo. Quanto mais complexo e difícil o problema a ser resolvido, mais tempo envolve. Portanto, o uso do computador é de utilidade específica e limitada no estudo do direito e não deve ser exagerado já que processos judiciais não são uma linha de montagem computadorizada mas envolvem empregos, fortunas, héranças, direitos individuais, a liberdade das pessoas e sua felicidade.

\section{A comercialização da prática do direito}

Este é um tema particularmente penoso. A comercialização trivial da prática do direito, sob a capa do profissionalismo, causa um mal estar generalizado e também envolve aspectos éticos. Nota-se uma ênfase exagerada, generalizada, neste sentido da comercialização da advocacia.

Há advogados que no seu míster pouco se distinguem dos comerciantes. As áreas do direito mais afetadas por esta prática, que consideramos nefasta, são as áreas de cobrança, marcas e patentes, locações e buscas e apreensões em contratos de financiamento ao consumidor. Nestes setores da advocacia manifestam-se com mais crueza os aspectos de comercialização da prática do direito que abastardam a profissão.

Realmente é dificil achar uma solução para esta problemática, eis que também estes serviços precisam ser executados, são vitais mesmo para os credores, locadores, inquilinos, financiados e mutuantes, industriais e comerciantes envolvidos.

Talvez a solução para diminuir os aspectos comerciais mais contundentes destas formas de advocacia seria conscientizar os bacharéis em direito, aí atuantes, que também esta advocacia, embora massificada e em série, é uma atividade nobre que merece ser prestigiada.

Muito depende do comportamento e da atividade dos que atuam nestas áreas.
Não há razão por que a advocacia nestas e noutras áreas de serviços jurídicos massificados não seja de cunho nobre e valioso. Dado o tratamento e enfoques corretos, o aspecto de atividade mercantilizada pode ser afastado.

A advocacia, a prática do direito, é uma profissão de cunho público.

Não estatal, mas público no sentido de bem comum, do interesse de todos, do interesse público. A advocacia, tradicionalmente, é uma das três profissões que nos séculos passados eram consideradas profissões eruditas: o direito, a medicina e o ministério religioso. Por isso também, a exigência, por ocasião da formatura, do juramento.

Deve portanto o advogado auxiliar na tarefa de defender a vida, o patrimônio, a liberdade, os direitos fundamentais e a busca da felicidade dos cidadãos de uma nação democrática. 